\section{Two BASIC programs to compare elements within and among correlation matrices}

\author{
JULIA L. BIENIAS \\ University of Illinois at Urbana-Champaign, Champaign, Illinois
}

Sometimes it is necessary to compare correlations for statistical homogeneity. To compare elements within a single correlation matrix, standard tests for comparing correlations are inappropriate, as the correlations are measured on the same individuals. Steiger (1980) has described a procedure for comparing related correlations. The first program described here (STEIGER.BAS) uses his generalized formula for comparing two correlations, pooling the correlations being compared (p. 247). The test statistic is a standard normal deviate.

J. Cohen and P. Cohen (1983) describe a procedure for testing two or more correlations for homogeneity. The procedure assumes each correlation is computed on a different set of individuals. The correlations are transformed to standard normal deviates using Fisher's procedure. The test statistic is a chi-square. The second program described below (COHEN.BAS) uses J. Cohen and P. Cohen's formula (1983, p. 55), which can accommodate any number of correlations to be tested.

Input. STEIGER.BAS: Steiger's formula uses six correlations among four factors of interest: The correlation between factor $j$ and factor $k(r(j, k))$, the correlation between factors $h$ and $m(r(h, m))$ (the two correlations being compared), and the four remaining correlations among the factors. The user is first asked whether the two correlations share a common factor, that is, whether the two correlations are of the form $r(j, k)$ and $r(j, m)$. The user is asked interactively to input the names of the factors associated with the correlations. Finally, the user is prompted to input the two correlations of interest and the remaining correlation(s). It is assumed that the user has checked the correlations for internal consistency (e.g., see J. Cohen \& P. Cohen, 1983, p. 280).

COHEN.BAS: The user is asked interactively to input the correlations to be tested for homogeneity, along with their sample sizes.

To compute the Fisher $r$-to- $z$ transformations, the programs substitute .9999 for a correlation of 1 and -.9999 for a correlation of -1 , since a $z$ corresponding to $r=1$ is infinite. This is done only when the correlation is to be transformed; in any other calculations, a correlation of 1 is used. Both programs include error-checking routines that display the correlations that have been input and prompt the user to change them if necessary (see Table 1).

The author would like to thank Michael J Strube and two anonymous reviewers for their instructive comments. Address correspondence to Julia L. Bienias, Department of Psychology, University of Illinois, 603 E. Daniel, Champaign, IL 61820.
Table 1

Example of Error-Checking Routine Screen Display

STEIGER.BAS*

Here are the values you have input. Please check them.

The correlation between $F 1$ and $V 1$ is .5

The correlation between $F 2$ and V2 is .6

The correlation between $F 1$ and F2 is .7

The correlation between $F 1$ and V2 is .5

The correlation between V1 and V2 is .8

The correlation between $\mathrm{V} 1$ and $\mathrm{F} 2$ is .5

Are these values correct? $(y / n)$

\section{COHEN.BAS $\dagger$}

Here are the correlations you have just input, along with their sample sizes and the number of the observation. Please check them.

\begin{tabular}{rll} 
Obs. & $\frac{\mathrm{r}}{\mathrm{N}}$ & $\frac{\mathrm{N}}{67}$ \\
\hline 1 & .72 & 93 \\
2 & .41 & 73 \\
3 & .57 & 98 \\
4 & .53 & 82 \\
5 & .62 & 39 \\
6 & .21 & 91 \\
7 & .68 & 27 \\
8 & .53 & 75 \\
9 & .49 & 49
\end{tabular}

Are these correct? $(y / n)$

"Data are from "Tests for Comparing Elements of a Correlation Matrix" by J. H. Steiger, 1980, Psychological Bulletin, 87, 249. †Data are from Applied Multiple Regression/Correlation for the Behavioral Sciences (2nd ed.) by J. Cohen and P. Cohen, 1983, Hillsdale, NJ: Erlbaum.

Output. STEIGER.BAS calculates the standard normal deviate for the comparison. COHEN.BAS calculates the chi-square for the comparison. Output consists of a title and explanatory remarks for the analysis as well as the result. The user has a choice of whether to display the output on the screen or to send it to a printer. Sample output for Program I is presented in Table 2.

Program Language and Requirements. Both programs are written in Microsoft GW-BASIC for an IBMPC or compatible computer. Program I consists of 158 lines, including REMark statements, and Program II contains 104 lines. No IBM-specific functions are included so that the program can be easily adapted to other microcomputer versions of BASIC.

Availability. A listing of the programs may be obtained

Table 2

Sample Output*

The comparison of the correlation between $F 1$ and $V 1$ with the correlation between $\mathbf{F} 2$ and $\mathrm{V} 2$

(Corresponding Fisher $\mathrm{Zs}$ are .5493061 and .6931472 )

was not significant at alpha $=.05, \mathrm{z}=-1.399394$

The standard error of the difference is .1027881

"Data are from "Tests for Comparing Elements of a Correlation Matrix" by J. H. Steiger, 1980, Psychological Bulletin, 87, 249. 
by writing to the author. A disk copy may be obtained by sending a double-sided, double-density diskette in a reusable diskette mailer. Program users with suggestions or questions about the program are welcome to write to the author.

\section{REFERENCES}

COHEN, J., \& CoHen, P. (1983). Applied multiple regression/correlation for the behavioral sciences (2nd ed.). Hillsdale, NJ: Erlbaum.

STEIGER, J. H. (1980). Tests for comparing elements of a correlation matrix. Psychological Bulletin, 87, 245-251.

(Revision accepted for publication December 11, 1986.)

\title{
NOTICE
}

\author{
Fourth International Symposium on Aviation Psychology \\ Columbus, Ohio \\ April 26-30, 1987
}

The Fourth International Symposium on Aviation Psychology, which is sponsored by the Association of Aviation Psychologists and the OSU Aviation Psychology Laboratory, will be hosted by The Ohio State University in Columbus, Ohio, on April 26-30, 1987.

For further information, please contact: Richard S. Jensen, Aviation Psychology Lab, Department of Aviation, The Ohio State University, Box 3022, Columbus, Ohio 43210-0022 (Telephone: 614-422-1116).

\section{Fechner Centennial Symposium on Foundational Problems of Psychophysics \\ Bonn, West Germany \\ June 24-27, 1987}

In honor of the G. Th. Fechner centennial, the Psychological Institute of the University of Bonn is organizing a symposium on foundational problems of psychophysics to be held in Bonn June 24-27, 1987. The aim of the symposium is to evaluate current trends in psychophysical theory-with an emphasis on visual perception-from the perspectives of perception, psychophysics, neurophysiology, computer vision, and abstract measurement theory.

Speakers will include: M. Akita (Kyoto), D. Albert (Heidelberg), W. H. Batchelder (Irvine), R. Boynton (San Diego), H. Colonius (Oldenburg), J. Drösler (Regensburg), J. Cl. Falmagne (New York), G. Geissler (Leipzig), R. L. Gregory (Bristol), R. A. M. Gregson (Armidale), A. Hajor (Giessen), T. Indow (Irvine), H. Irtel (Regensburg), B. Julesz (Murray Hill), R. D. Luce (Harvard), J. Lukas (Regensburg), D. I. A. MacLeod (San Diego), L. Narens (Irvine), E. Pöppel (München), T. Poggio (MIT), W. Prinz (Bielefeld), R. N. Shepard (Stanford), L. Spillmann (Freiburg), D. Vorberg (Marburg), B. Wandell (Stanford), J. Yellott (Irvine).

The registration fee is $\$ 75$ ( $\$ 35$ for students). For further information, please contact: Rainer Mausfeld, Department of Methodology and Statistics, Psychological Institute, University of Bonn, Roemerstr. 164, D-5300 Bonn 1, West Germany. 